\title{
Geomorphology Urban Platform for Media Sig: Monitoring Process Erosive Accelerated (Gully) Cemetery in Archaeological Indigenous Manaus
}

\author{
Marcio de Jesus Lima do Nascimento ${ }^{1}$, Ricardo Jorge Amorim de Deus ${ }^{2}$, Jandecy Cabral Leite ${ }^{3}$
}

\author{
${ }^{1}$ Laureate Internacional Universities (UNINORTE). Rua Joaquim Nabuco, No 1615.Manaus -Amazonas -Brasil. CEP:69020-030. \\ ${ }^{2}$ Programa de Pós-Graduação em Ciência e Meio Ambiente (PPGCMA) da Universidade Federal do Pará/UFPA Rua Augusto Corrêa \\ No. 01. Guamá, Belém - Pará, CEP: 66075-110. \\ ${ }^{3}$ Instituto de Tecnologia e Educação Galileo da Amazônia (ITEGAM). Av. Joaquim Nabuco No 1950. Centro. Manaus - AM. Brasil. \\ CEP: 69005-080.
}

Email: marciosavatage@gmail.com,dedeus@ufpa.br, jandecy.cabral@itegam.org.br.

Received: February 06 0 th 2017

Accepted: February $24^{\text {th }}, 2017$

Published: March 30th 2017

Copyright $\odot 2016$ by authors and Institute of Technology Galileo of Amazon (ITEGAM). This work is licensed under the Creative Commons Attribution International License (CC BY 4.0).

http://creativecommons.org/licenses/by/4.0/ (c) (1) (3) Opea Acceste

\begin{abstract}
The studies are limited directly in the erosive processes becoming more and more present in the urban centers of Manaus. The objective of this research is to analyze the anthropogenic impacts of the accelerated erosive process (gully) at a point in the Northern Zone of Manaus, the study is being directed to monitor the accelerated erosive process in a gull, located in the Archaeological Cemetery Indigenous in the New Town District, according to the census of the (IBGE), its population was 59. 576 in habitants in 2010, we intend to understand the active processes that detonate the balance in the erosive system and archaeological vestiges in the urban environment in the area with formation of gully, The methods to be approached are quali-quanti, we can consider that the type of research is intended to be descriptive and field studies, so that we can deepen the knowledge of reality, because we explain the reason of the facts.
\end{abstract}

Keywords: Environment, Erosion, Gullies, Geomorphology.

Geomorfologia Urbana por Meio de Plataforma SIG: Monitoramento do Processo Erosivo Acelerado (Voçoroca) no Cemitério Arqueológico Indígena de Manaus

\begin{abstract}
RESUMO
Os estudos limitam-se diretamente nos processos erosivos tornando-se cada vez mais presentes nos centros urbanos de Manaus. Desta forma, objetivo da pesquisa é, analisar os impactos antropogênicos decorrentes ao processo erosivo acelerado (voçoroca) em um ponto da Zona Norte de Manaus, o estudo está sendo direcionado no sentido de monitorar o processo erosivo acelerado em uma voçoroca, localizado no Cemitério Arqueológico Indígena no Bairro do Nova Cidade, conforme o censo do (IBGE), sua população era de 59.576 habitantes em 2010, pretendemos entender os processos atuantes que detonam o equilibrio no sistema erosivo e vestigios arqueológicos no meio urbano na área com formação de voçorocas, os métodos a serem abordados são quali-quanti, podemos considerar que o tipo de pesquisa tem como finalidade ser descritiva e estudos de campo, para que possamos aprofundar os conhecimentos da realidade, pois explicar a razão dos fatos.
\end{abstract}

Palavras Chaves: Ambiente, Erosão, Voçoroca, Geomorfologia. 


\section{INTRODUÇÃO}

Os processos erosivos tornam-se cada vez mais presentes nos centros urbanos, principalmente nas zonas de cobertura sedimentar recente, contendo sedimentos inconsolados e friáveis, desenvolvimento das ravinas e voçorocas descrito na literatura brasileira é geralmente atribuído a mudanças ambientais induzidas pelas atividades humanas. A grande maioria de trabalhos na literatura sobre as ravinas e voçorocas mostra que sua ocorrência está associada a formações sedimentares arenosas, mas há também exemplos de voçorocas em solos provenientes de rochas cristalinas. Segundo alguns trabalhos, a geologia das regiões do embasamento cristalino, com suas abruptas variações laterais, influi intensamente na propagação do voçoroçamento. Contatos geológicos, diques ou até mesmo bandas internas à rocha de composição diferente são suficientes para acelerar, impedir ou desviar a propagação de uma voçoroca.

Em Manaus as Zonas Norte e Leste são as áreas da cidade onde existem maiores concentrações de processo erosivos, devido a presença de compartimentos susceptíveis a erosão devido a declividades elevadas e numerosas cabeceiras de drenagem. $\mathrm{Na}$ cidade é com uma existência de conjuntos e bairros consolidada nas áreas planas em topo de tabuleiro com ruas chegando até as bordas. A falta de sistemas adequados de drenagem a de águas pluviais e o traçado inadequado do sistema viário faz com que as águas sejam lançadas nos limites das bordas das colinas, local mais susceptível a erosão, resultando no desencadeamento de processos erosivos. Movimentos de massa.

Os deslizamentos compõem o grupo de fenômenos naturais relacionados com a geomorfologia, o intemperismo, a erosão e a acomodação do solo, porem em áreas urbanas transformam se em fenômenos com alto grau de risco [1]. Em áreas urbanas em Manaus, os movimentos gravitacionais de massa ocorrem com relativa frequência em áreas de encostas desestabilizadas por ações antrópicas, provocando graves desastres, que costumam ocorrer de forma súbita [2], descreve que esta expansão urbana está associada à crise econômica instalada no final da década de 80 , que gerou a diminuição de empregos nas indústrias da Zona Franca, e vem, constantemente, aumentando o número de áreas de risco na capital. A presente pesquisa pretende, analisar os impactos antropogênicos decorrentes ao processo erosivo acelerado (voçoroca) em um ponto da Zona Norte de Manaus e entender os processos atuantes que detonam o equilibrio no sistema erosivo e vestigios arqueológicos no meio urbano, conhececendo na prática a aplicação do SIG com base na coleta de dados in loco por meio de sensores de captação de dados por GPS e imageamento por VANT (Veículo aéreo não tripulado).

Desta forma, o estudo está sendo direcionado no sentido de monitoramento do processo erosivo acelerado em uma voçoroca no Cemitério Arqueológico Indígena Bairro do Nova Cidade.

II.

II. CARACTERÍSTICAS E TEÓRICO-CONCEITUAIS DE GEOMORFOLOGIA URBANA E EROSÃO DO SOLO

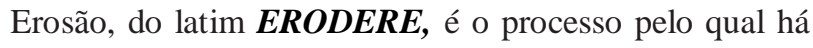
remoção de uma massa de solo de um local e sua deposição em outros locais, como resultado da ação de forças exógenas. A força motriz do processo é a energia cinética dos agentes erosivos. Com a diminuição progressiva da energia cinética do agente erosivo, dáse a deposição do material erodido. A água e os ventos são os principais agentes da erosão do solo, sendo a erosão hídrica a erosão ocasionada pela água de chuva ou de enxurrada, e a erosão eólica a erosão causada pelos ventos, a erosão hídrica é amplamente disseminada na maioria das regiões [3].

A erosão de solos é um fenômeno verificado em praticamente toda a superfície terrestre, em especial nas áreas com clima tropical onde os totais pluviométricos superam às demais regiões do planeta [4]. A desproteção do solo, e as grandes quantidades pluviométricas são as condições iniciais para que o solo eroda com mais facilidade. Quanto à origem dos processos erosivos iniciais, entende-se que os mesmos têm sua gênese tanto por processos naturais que são constituintes da formação do relevo terrestre (como também são naturais os fenômenos climáticos que regem a dinâmica erosiva inicial), tanto por práticas/usos indevidos do solo por parte do homem, acelerando assim tal processo[5].

Em termos gerais, pode-se dizer que a erosão apresenta a destruição das reentrâncias ou saliência do relevo, tendendo a um nivelamento, no entanto, a erosão pode ser dividida em dois grupos: a erosão natural e a erosão acelerada.As proprias condições naturais podem juntos com o manejo inadequado acelerar a degradação. Chuvas concentradas, encostras deprotegidas de vegetação, contato com solo-rocha abrupto, descontinuidades litólogicas e pedológicas encosta íngrimes são algumas condições naturais que podem acelera o processo. Apesar das causas naturais, por si só,detonarem processos de degradação ambiental, a ocupação humana desordenada, aliada às condições naturais de risco, podem provocar desastres, que envolvem, muitas vezes, prejuídos materiais e perda humana.

Concomitantemente, tal crescimento ocorreu sobre espaços herdados da natureza que foram apropriados para fins de habitação. Estes novos espaços de moradia se constituíram, em sua maioria, sem infraestrutura adequada e em áreas potencialmente vulneráveis, como as margens alagáveis de igarapés e encostas susceptíveis aos processos erosivos, dando origem àquilo que se convencionou chamar "áreas de risco". É própria da cidade a formação de áreas de risco quando a dinâmica da natureza entra em contato com a dinâmica da sociedade, em outras palavras, a falta de planejamento associada à dinamicidade dos processos naturais existentes, principalmente às intensas chuvas, constituem áreas de risco [6].

O conhecimento dos mecanismos que ditam os processos erosivos segundo [7], é fundamental quando se trata da elaboração de projetos de controle da erosão Entendemos que as práticas de conservação de solos bem como a recuperação de áreas degradadas não são tarefas fáceis de serem executáveis, pois, envolve uma quantidade considerável de variáveis a serem analisadas e discutidas antes de qualquer profissional da área propor quaisquer tipos de plano de controle/conservação do solo e áreas degradadas.

Quando tratamos do assunto da "erosão de solos" e sua posterior recuperação, muitos já vêm à mente que tal processo é causado único e exclusivamente pelo homem, entretanto, apesar de pertinente tal relato, [7] aponta que "ravinas e voçorocas são feições erosivas que caracterizam, no Brasil e em outras partes do mundo, antigos depósitos sedimentares cuja idade pode atingir mais de 20.000 anos AP., sendo, portanto, no que diz respeito, 
anteriores aos primeiros humanos documentados na América do Sul.

A erosão urbana no Brasil distingue-se das formas de erosões naturais e suas derivadas rurais por seus novos condicionantes, seus mecanismos exclusivos, os grandes volumes de materiais envolvidos e o papel representado pelo assoreambito. Uma gradual redução da presença de solos no assoreamento, acompanha a consolidação urbana. Verifica-se o incremento tanto relativo quanto absoluto dos resíduos urbanos como: lixo, entulho, matéria orgânica, resíduos industriais [8]. A erosão é um processo mecânico que se desenvolve na superfície causando profundidade em certos tipos de solos e sobre determinadas condições físicas de forma natural significante, transformando-se critica pela açâo modificadora do homem. O transporte e movimentação de partículas do solo, subsolos e rochas em decomposição pelas águas, ventos, assim dando surgimento ao processo erosivo [9].

O estudo dos processos erosivos vem sendo feito há diversas décadas, em todo o mundo. Para tal, os pesquisadorebXêm lançado mão de uma série de métodos e técnicas, dependendo dos objetivos do estudo, dos recursos humanos e financeiros disponíveis, das condições climáticas, dos tipos de solos, das condições ambientais e de outras características relevantes para o tema em questão [4[10][11][12][13][14][15][16].

Destacamos que a erosividade das chuvas, a erodibilidade do solo, a declividade do terreno, o manejo e as prâticas conservacionistas do solo são fatores que influenciam nas taxas de perda de solo [17]. Os processos erosivos também respondem por grande parte dos riscos na cidade. Segundo [18]. Conceitua a erosão como um resultado do impacto sobre as propriedades físicas do solo, e impacta o meio ambiente. Observa-se uma inadequação do planejamento de uso do solo ao se deparar com o crescente número de habitações implantadas em locais inadequados e sem elaboração do devido estudo de impacto ambiental. A erosão é um processo mecânico que age em superfície e profundidade, em certos tipos de solo e sob determinadas condições físicas, naturalmente relevantes, tornando-se críticas pela ação catalisadora do homem. Traduz-se na desagregação, transporte e deposição de partículas do solo, subsolo e rocha em decomposição pelas águas, ventos ou geleiras [19].

Para os estudos de erosão é preciso diferenciar o escoamento difuso do escoamento concentrado. O escoamento difuso ocorre através de uma rede de canais anastomosados, que se movimenta por canalículos de forma difusa, em função das características do micro relevo e rugosidade da superfície. Este se forma pelo volume além daquele que ficou armazenado nos micros depressões e não infiltrou. O escoamento concentrado ocorre com o acúmulo do volume de água, proveniente do escoamento difuso, formando sulcos bem definidos e com maior velocidade que o escoamento difuso [20]. A erosão hídrica pode manifestar-se de três formas principais: erosão laminar ou em lençol; ravinamentos; e sulcos ou voçorocas. A erosão laminar caracteriza-se pelo desgaste e arraste uniforme e suave em toda a extensão sujeita ao agente. Outro fator condicionante na erosão hídrica é o topográfico, devido ao grau de inclinação do terreno e pelo comprimento de rampa, sendo de suma importância na concentração, dispersão e velocidade de escoamento superficial [17]. A erosão hídrica, à qual daremos ênfase, desenvolve-se em quatro estágios: formação de canal onde há concentração de escoamento; incremento rápido em profundidade e largura onde a cabeceira move-se para montante; declínio do aumento com início de crescimento da vegetação natural; e eventual estabilização com o canal locado num perfil de equilíbrio com paredes estáveis e vegetação desenvolvida segurando o solo [19].

A matéria orgânica e as partículas de argila são as primeiras porções do solo a se desprenderem, sendo as partes mais ricas e com maiores quantidades de nutrientes para as plantas. Apesar de ser de difícil observação ela pode ser constatada pelo decréscimo de produção das culturas, pelo aparecimento de raízes ou mesmo marcas no caule das plantas, onde o solo tenha sido arrastado [19].

A erosão do solo é um processo natural, praticamente impossível de ser estancado, comumente difícil de ser controlado, e facilmente acelerado pelo homem. A erosão se manifesta pela deterioração da superfície do solo, como uma perturbação em superfície, acompanhada pela remoção de partículas individuais constituintes do solo ou de volumes inteiros de solo.

O fenômeno da erosão consiste na ação combinada de um conjunto de fatores que provoca a desagregação e o transporte de partículas do solo ou fragmentos e partículas de rocha sobre a superfície terrestre. Desta forma, é no ordenamento do território que o contributo da geomorfologia pode ter uma aplicação prática, colocando à disposição da sociedade o conhecimento adquirido.

\section{II.1 EROSÃO POR SALPICAMENTO (GOTA D’ÁGUA)}

A capacidade das gotas de chuva de desprender partículas ou grupamentos de partículas depende de dois fatores, da energia cinética que elas atingem no movimento de queda e das propriedades do solo. Quanto maior a energia cinética e menor agregação entre as partículas de solo, maior será o desprendimento. [21]. Após eventos chuvosos, a água precipitada segue várias direções: uma parte cai diretamente na superfície do terreno (devido à falta de vegetação ou entre os espaços existentes na vegetação); outra parte é interceptada pela copa das árvores, da qual uma parte é evaporada (evapotranspiração) ou ainda chega ao solo ou por gotejamento das folhas (transprecipitação) ou por escoamento de tronco (fluxo de tronco). No caso em que a água cai direta ou indiretamente no terreno, pode ocorrer a erosão por salpicamento (splash erosion), desde que a superfície do terreno esteja desprovida de proteção (serapilheira e/ou camada orgânica). [17][21].

O impacto das gotas de chuva destrói os agregados do solo em partículas menores, as quais são lançadas em várias direções a uma distância que vai de milímetros a dezenas de centímetros. O gotejamento sobre o solo provoca a erosão por salpicamento (splash erosion) onde a energia cinética das gotas de chuva provoca a desagregação do solo sem cobertura vegetal [22].

A erosão por splash, também conhecida no Brasil, como erosão por salpicamento, ocorre, basicamente, como um resultado das forças causadas pelos impactos das gotas de chuva. Uma gota de chuva, quando bate em um solo molhado, remove as partículas que estão envolvidas por uma película de água [4]. Estando desprotegido de vegetação ou mesmo das práticas conservacionistas, o solo sofre uma ação de desagregação como impacto da gota de chuva, que depois arrasta-o, principalmente nos primeiros minutos da chuva [23].

A quantidade de solo arrastado depende muito do seu tipo, declividade do terreno e da intensidade da chuva. Dependendo do seu diâmetro, as gotas das chuvas desagregam as partículas do solo e a velocidade do escoamento das águas arrastam grande 
quantidade de solo, chegando até uma percentagem na ordem de $0,25 \%$ a $5,5 \%$ desolo arrastado de acordo com o volume de água escoado, como demonstrado pelas figuras 1 e 2 .

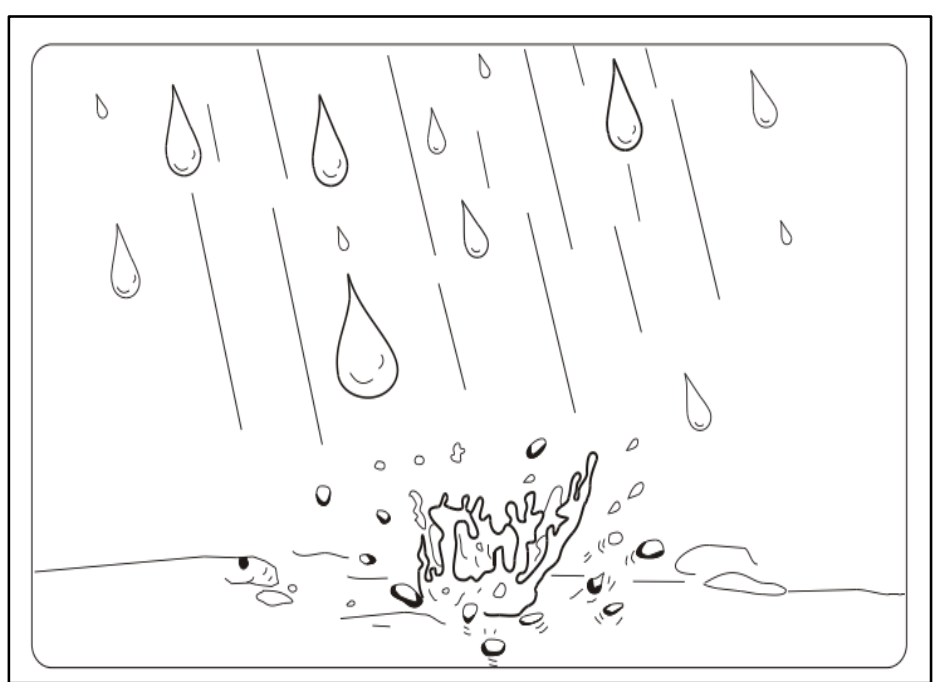

Figura 1: Processo de detonação do solo.

Fonte: [23].

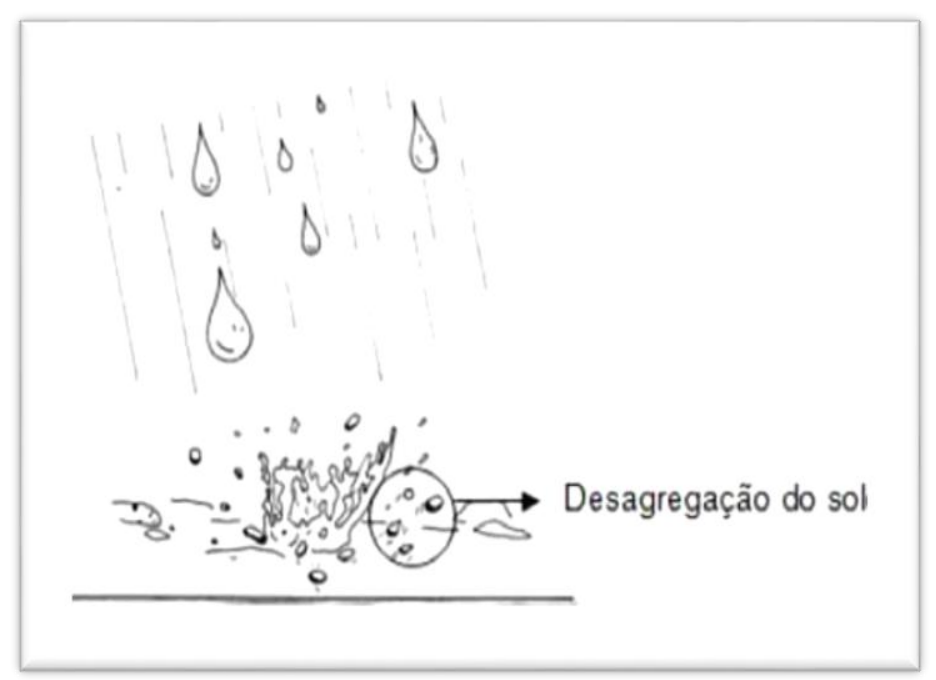

Figura 2:Processo de desagragação do solo Fonte:[23].

A erosão é o processo de desprendimento, arraste e deposição de partículas do solo causado pela água e pelo vento ". A desagregação das partículas do solo é ocasionada tanto pelo impacto direto das gotas de chuva no solo (efeito de splash), como pelas águas de escoamento. As gotas de chuva atingem a superfície com a velocidade em 5 a $15 \mathrm{Km} /$ hora, enquanto a agua da enxurrada tem velocidade bem menor usualmente não maior de 1 $\mathrm{km} /$ hora.

O primeiro passo para erosão é, portanto, o impacto direto das gotas de chuva, que provoca forte desagregação das partículas de solo desprovidos de vegetação. Se a superfície do solo está revestida com mapa, a copa das árvores absorve a maior parte de energia cinética das gotas de chuvas e o manto das folhas sobre o solo amortece o restante do impacto, advindo do segundo trajeto, das copas até a superfície do terreno [17][24[25].

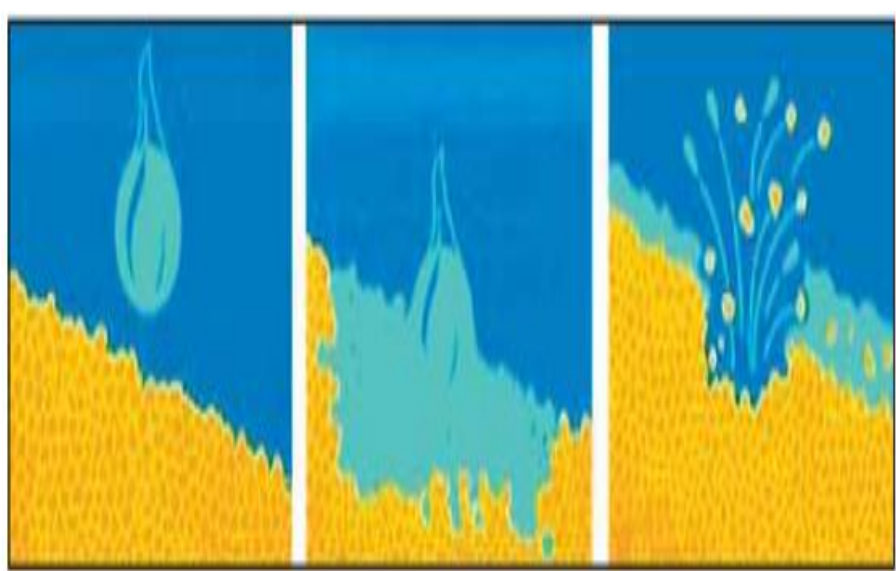

Figura 3: Processo exato de Desagregação do solo impactado pela gota da chuva. (Splash).

Fonte: [3].

A gota descreve uma curva parabólica, que se move lateralmente, mais ou menos quatro vezes à altura do deslocamento. O splash ocorre tanto para baixo como para cima em uma encosta, mas quase sempre as partículas são transportadas para baixo três vezes mais distante do que para cima. Além de as partículas serem transportada pelo impacto causado pela gota de chuva, algumas são deslocadas pelo choque proporcionado por sedimentos que se batem uns contra outros.

A vegetação tem um papel fundamental na contenção de erosões, sendo que a cobertura vegetal é a defesa natural de um terreno contra os processos erosivos. Quando a Erosividade da chuva é constante, o fluxo de solo devido a erosão por Splash é uma função gradiente da encosta, porque a distância média percorrida pelas partículas depende da declividade. O significado de splash, em condições de escoamento superficial, depende da profundidade do fluxo. Conforme [4], a erosão por splash pode diminuir em um determinado tipo de solo, especialmente se o próprio splash formar crosta na superfície. Este processo de salpicamento é agravado de acordo com a intensidade da chuva, ou a energia cinética da chuva, pois quanto mais intensas maiores serão as gotas de água que atingiram o solo.

O processo da ação da água pluvial, intercepta as gotas das chuvas evitando o desenvolvimento do efeito splash. Também age no que diz respeito à saturação do solo, quando ao sugar os nutrientes deixa a porosidade maior, aumentando o nível de água que o mesmo suporta e consequentemente evitando o escoamento. [26]. As gotas da chuva conforme seu tamanho e energia cinética são responsáveis pela ruptura do material e seu transporte por salpicamento. A declividade e o comprimento de rampa interferem na velocidade de escoamento da água (velocidade da enxurrada) e no volume de água infiltrado. $\mathrm{O}$ solo, de acordo com suas características físicas e químicas, apresenta diferentes níveis de suscetibilidade à erosão. A cobertura vegetal contribui reduzindo o impacto das gotas da chuva, além de diminuir a velocidade do escoamento, pela criação de obstáculos ao fluxo e auxilia no aumento do volume infiltrado, por meio dos biocanais (raízes). [27]. A capacidade das gotas de chuva de desprender partículas ou grupamentos de partículas depende de dois fatores, da energia cinética que elas atingem no movimento de queda e das propriedades do solo. Quanto maior a energia cinética e menor a agregação entre as partículas de solo, maior será o desprendimento. A partícula desprendida poderá seguir dois caminhos, manter-se 
relativamente livre na superfície do solo e ser transportada quando da ocorrência de fluxo superficial ou iniciar um movimento descendente através dos poros do solo favorecendo, em certos casos, a sua colmatação e gerando as chamadas crostas.

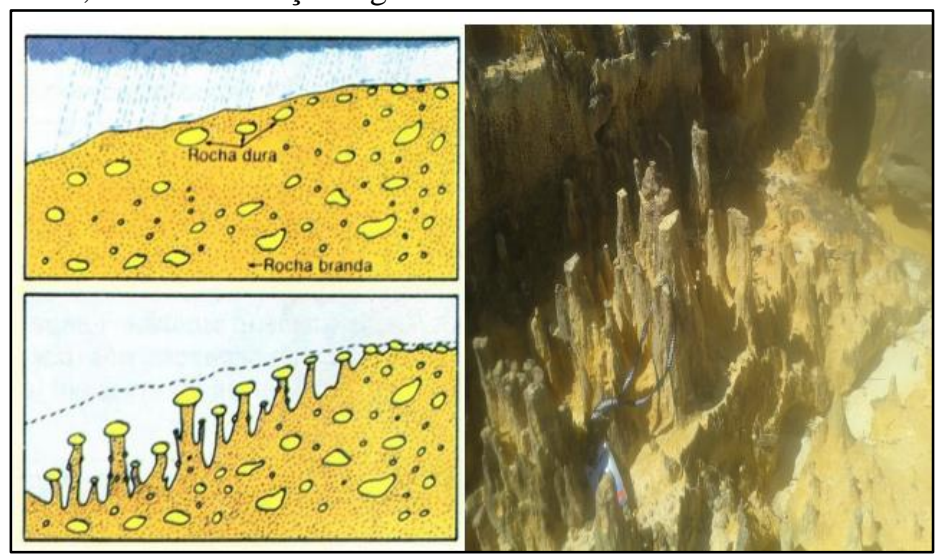

Figura 4: Cchaminés de fada, Pedestais, Demoiselles. Fonte: [28].

As chaminés de fada são formas de relevo muito curiosas. Formam-se a partir de depósitos detríticos pouco coerentes e muito diversificados em tamanho. Podem coexistir desde argilas e areias. A ação da chuva vai provocar uma erosão diferencial: os materiais mais finos serão erodidos enquanto que os materiais mais volumosos e mais rígidos serão mais poupados ao trabalho de desgaste das águas de escorrência. Contudo, a erosão não afetará os materiais por baixo dos grandes blocos de rochas. A rocha de cima funciona como protetor da erosão e acabará por colapsar quando, com o continuar da erosão, não seja possível sustentar o bloco de rocha maior. São formas de relevo raras e ocorrem, sobretudo em áreas montanhosas onde existam depósitos de vertente, em particular depósitos glaciários que são aqueles em que a diversidade de tamanho dos detritos é, normalmente, maior.

Os pedestais (demoiselles) são feições comuns nas superfícies erodidas e relacionados à erosão por salpicamento e ao escoamento superficial difuso, cuja formação se dá geralmente quando um material mais resistente (grânulos, seixos, folhas e outros) dificulta a ação da erosão por salpicamento, esculpindo formas residuais [21]. Este processo de salpicamento é agravado de acordo com a intensidade da chuva, ou a energia cinética da chuva, pois quanto mais intensas maiores serão as gotas de água que atingiram o solo. Segundo [28] a água é a principal responsável pelas mudanças morfológicas da paisagem, contribuindo significativamente para sua evolução. Desse modo, é importante analisar a erosão hídrica, que atua de forma direta (impacto das gotas de chuva na superfície do solo, no caso o splash) e indireta, promovendo o escoamento superficial mediante a saturação do perfil de solo e o selamento da sua superfície. A ação erosiva é controlada por dois fatores: erosividade (habilidade da chuva e do escoamento em gerar erosão); erodibilidade (características do solo relacionadas ao favorecimento ou não da erosão).A suscetibilidade dos solos a erosão correlaciona-se com as relações sociais de propriedade e com o acesso das diferentes classes sociais (...), fazse crítica principalmente a forma como o sistema capitalista se mostra, tal qual se dá a suas distribuições de infraestrutura e capital, propiciando o investimento quase que inteiramente nas áreas centrais das cidades. Dessa forma as localidades periféricas dos municípios ficam mais susceptíveis as dinâmicas superficiais que permeiam o perímetro urbano [28].

Toda via pode-se analisar que na área urbana não existe essa proteção natural que "contem" as erosões, por isso é necessária uma maior manutenção das áreas que podem ser afetadas pelos processos erosivos [17]. Grande quantidade de solo pode ser removida desde que suas partículas estejam desagregadas e suspensas nas aguas das enxurradas, porque isto as torna suscetíveis transportadas. A facilidade com que uma partícula é transportada depende de seu tamanho: argila, o silte e a matéria orgânica são facilmente carregadas pelas águas devido ao pequeno peso e dimensão de suas partículas.

\section{II.2 CONCEITOS E CLASSIFICAÇÃO DE VOÇOROCAS}

As voçorocas se enquadram com o as feições erosivas de maior impacto ambiental, uma vez que suas características dimensionais, em geral, maiores que os sulcos e ravinas, e principalmente sua morfo dinâmica quase sempre altera de forma significativa a paisagem. De acordo com [25]: “[...] as voçorocas são formas resultantes de processos erosivos acelerados que evoluem no tempo e no espaço". Por isso, a análise do espaço temporal dos processos erosivos favorece a compreensão da dinâmica da erosão e, consequentemente, na adoção de práticas de conservação dos solos. Quando os fatores acima descritos combinam-se com os elementos que atuam sub superficialmente, as ravinas bastante evoluídas, cuja largura já atinge alguns metros, aprofundam-se atingindo o lençol freático fazendo com que este aflore à superfície. Neste estágio do processo erosivo a forma resultante é conhecida como voçoroca, ou boçoroca (que em Tupi "Yby-çoroc" significa "terra-rasgada") e tem-se o quadro mais agravante cujos efeitos refletem-se na desconfiguração da paisagem e suas nocivas consequências às atividades humanas [14].

A voçoroca consiste no desenvolvimento de canais nos quais o fluxo superficial se concentra. Formam-se devido à variação da resistência à erosão, que em geral é devida a pequenas mudanças na elevação ou declividade dos terrenos. Voçoroca é o estágio mais avançado de erosão acelerada correspondendo à passagem gradual do processo de ravinamento, até atingir o lençol freático, com o aparecimento de surgências d'água. Para [21], o significado etimológico dos termos boçoroca ou voçoroca é proveniente da junção de duas expressões do tupi-guarani, sendo ibi (terra) esoroc (rasgão), ou seja, voçoroca (gully, em inglês) seria um "rasgão na terra". As voçorocas são canais d'água intermitentes, maiores do que as ravinas. Esses canais carregam água durante e imediatamente após as chuvas e, ao contrário das ravinas, as voçorocas não podem ser removidas pelo preparo normal do solo.

Segundo [25], "a ruptura dos agregados pode ser considerada um dos principais fatores no processo de erosão dos solos, pois é a partir dessa ruptura, que outros processos se desencadeiam no topo do solo desestabilizando-o e começando a ocorrer o processo erosivo". Outro fator que também deve ser considerado é a formação de crosta, porque ela torna o terreno compactado não deixando a água penetrar com facilidade, e esta ao percolar sobre terrenos com declividades acentuadas carrega os materiais inconsolidados deixando calhas sem seus lugares. As voçorocas tendem a se formar onde grandes volumes de escoamento superficial são concentrados e descarregados em encostas com solos erodíveis. Este processo é comum em pastagens 
e, é provavelmente, uma das principais formas de erosão em bacias hidrográficas [29]. No entanto, na evolução da voçoroca, outras feições erosivas atuam no interior desta em processos que resultam em sua expansão. Além disso, as diversas feições erosivas ali existentes demonstram diferentes tipos de mecanismos, denunciando o grau de resistência dos materiais e a intensidade de atuação da água [21].

Ressalta que o voçorocamento pode ser resultado do alargamento e aprofundamento de ravinas que se dá pela ação erosiva das águas na base e nas suas laterais, gerando, consequentemente, um colapso do material em suas laterais e em direção ao seu topo. Para [4], as voçorocas também podem se originar da erosão causada pelo escoamento sub-superficial, o que foi constatado pelas pesquisas realizadas por [4], as quais, indicaram o surgimento de voçorocas por escoamento subsuperficial em áreas com degradação da cobertura vegetal, sendo que, nessa situação, as chuvas de grande intensidade provocam fluxos sub-superficiais, os quais, ao removerem sedimentos, aumentam o diâmetro dos dutos pelos quais a água é transportada, provocando, por isso, um colapso no material localizado em superfície.

Segundo [11], voçoroca pode ser compreendida por "escavação ou rasgão do solo ou de rocha decomposta, ocasionado pela erosão do lençol de escoamento superficial. Suas características físicas associam-se a paredes laterais íngremes e geralmente possuem fundo chato no qual ocorre fluxo de água no seu interior durante eventos chuvosos. Vale salientar que uma voçoroca poderá alcançar a uma profundidade tal chegando a atingir o limite do lençol freático. As formas de erosão hídrica são determinadas conforme o grau de desagregação e transporte de partículas do solo, tendo nas voçorocas o estado avançado de erosão hídrica.

As voçorocas, no entanto, apresentam maior risco sendo as formas mais complexas e destrutivas de erosão linear. Em geral são ramificadas, de grande profundidade, apresentando paredes irregulares e perfil transversal em "U". Processos erosivos vinculados pela ação da água das chuvas, principal agente erosivo. Neste sentido para [7], ravinas e voçorocas podem ser assim definidas, ravinas e voçorocas podem ser consideradas como incisões que resultam da tendência de sistemas naturais a atingir um estado de equilíbrio entre energia disponível e eficiência do sistema em dissipar energia. De acordo com [13], as voçorocas são características erosivas permanentes nas encostas, possuindo paredes laterais íngremes e, em geral, fundo chato, ocorrendo fluxo de água no seu interior durante os eventos chuvosos.

Algumas vezes, as voçorocas se aprofundam tanto, que chegam a atingir o lençol freático. Os critérios adotados para seleção das voçorocas submetidas ao monitoramento, foram: diferentes uso e ocupação do solo; acessibilidade e a questão da segurança na coleta dos dados. Quando um sistema natural (encosta, bacia hidrográfica, etc.) não é eficiente para dissipar a energia disponível, o sistema e adapta, deforma a atingir novo estado de equilíbrio. No caso dos solos, tanto a mudança na quantidade de energia disponível (intensidade e frequência de precipitações, teor de umidade dos solos, etc.) quanto à alteração das características do sistema (uso do solo, cobertura vegetal, grau de estruturação, etc.). De acordo com [4] “[...] as encostas são um foco de grande atenção na pesquisa geomorfológica. Seu estudo é fundamental para a compreensão das paisagens naturais, bem como para a sua aplicação ao controle da erosão dos solos nas terras agrícolas e à prevenção contra a ocorrência de movimentos de massa”. Este mesmo autor considera que as encostas (ou vertentes) são palco da ação antropogênica, sendo que, devido à falta de planejamento adequado no uso e na ocupação do solo, pode acarretar sérios danos à estabilidade dos terrenos.

As voçorocas são características erosivas relativamente permanentes nas encostas, possuindo paredes laterais íngremes e, em geral, fundo chato, ocorrendo fluxo de água no seu interior durante os eventos chuvosos. Algumas vezes, as voçorocas se aprofundam tanto, que chegam atingir o lençol freático, comparados com os canais fluviais as voçorocas possuem, geralmente, maior profundidade e maior largura. Elas estão associadas com o processo de erosão acelerada e, dessa forma, com a instabilidade da paisagem. O desmatamento, o uso agrícola da terra, o super pastoreio e as queimadas, quase sempre, são responsáveis diretos pelo surgimento de voçorocas, associados com o tipo de chuva e as propriedades do solo e podem ter origens variadas, uma delas se refere ao alargamento e aprofundamento de ravinas, que se formam em uma determinada encosta [25].

Segundo [7][4][14] três tipos principais de voçorocas podem ser destacadas: as voçorocas conectadas à rede regional de canais, as desconectadas e aquelas que resultam da junção das duas anteriores. As voçorocas conectadas estariam associadas ao escoamento hipodérmico e/ou subterrâneo nas partes baixas da encosta, podendo ser considerada um canal de primeira ordem; as voçorocas desconectadas, encontrando-se na parte superior da encosta, estariam ligadas ao escoamento superficial e não poderiam ainda serem consideradas um canal de primeira ordem em virtude de não estarem ligadas à rede de drenagem; e o terceiro tipo, seria na verdade a junção das duas formas anteriores (voçorocas conectadas e voçorocas desconectadas), formando um só incisão erosiva [7].

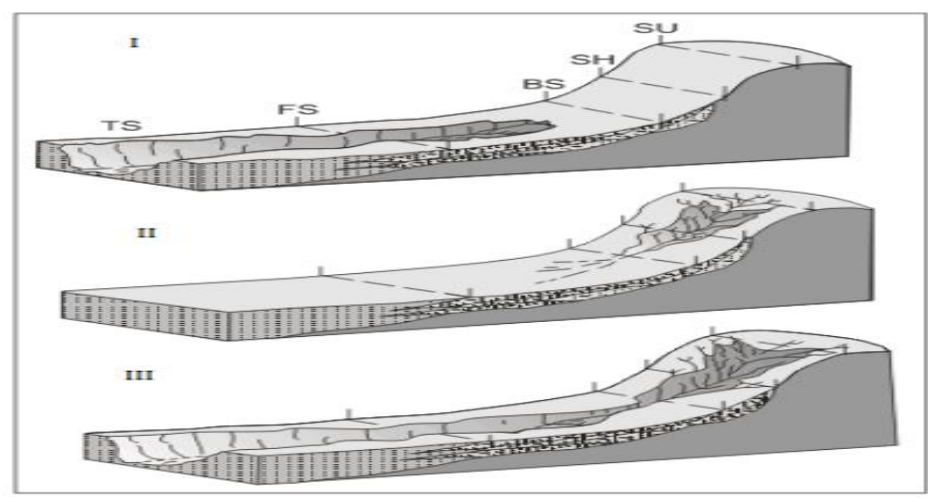

Figura 5: Modelo de evolução de voçorocas.

Fonte: Autores, (2016).

I: voçoroca conectada à rede hidrográfica;

II: voçoroca desconectada da rede hidrográfica;

III: integração entre os dois tipos anteriores.

A seta na figura 3 aponta para degraus formados no momento da integração. Sedo TS - toeslope; FS - footslope; BS backslope; SH shouder; SU - summit. Modificado de [7].

\section{II.3. CARACTERIZAÇÃO DA ÁREA DE ESTUDO}

No ponto de abordagem da pesquisa de campo ocorreu no sítio arqueológico urbano do Bairro Nova Cidade, Zona Norte de Manaus com uma alta densidade demográfica $\left(41 \mathrm{hab} / \mathrm{km}^{2}\right)$, onde localiza-se o cemitério arqueológico indígena no Bairro Nova Cidade é um bairro do município brasileiro de Manaus, capital do 
estado do Amazonas, localiza-se na Zona Norte da cidade. De acordo com o censo do Instituto Brasileiro de Geografia e Estatística (IBGE) [29], sua população era de 59. 576 habitantes em 2010, com crescimento populacional tem sido o principal responsável pela degradação ambiental que a mesma vem sofrendo, com as áreas de expansão desta zona tornam-se cada vez mais direcionados ao seu limite.

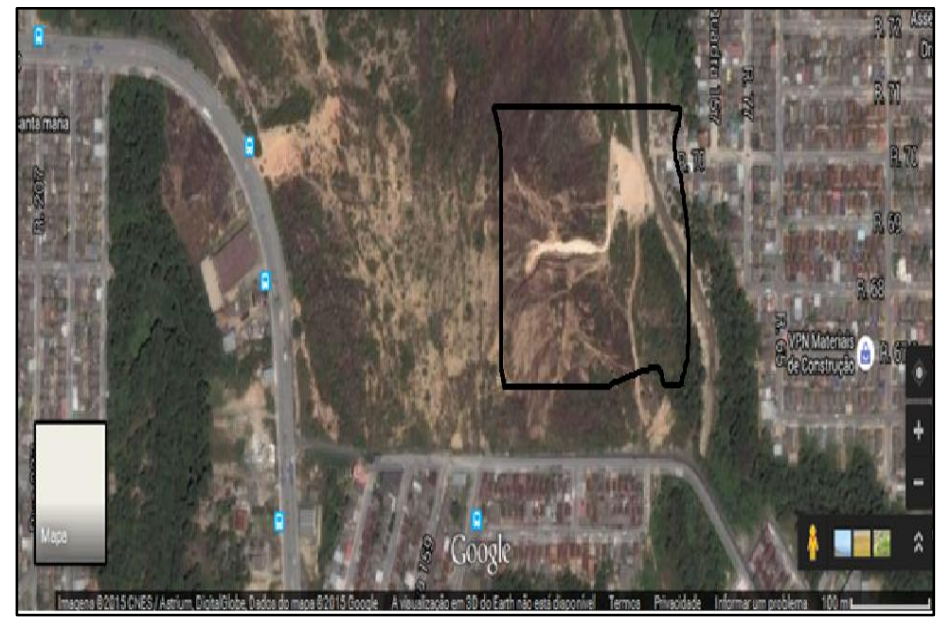

Figura 6: Caracterização da área de estudo- sítio arqueológico indígena do Nova Cidade.

Fonte: [30].

O sítio arqueológico do Nova Cidade localiza-se na Zona Urbana da Cidade de Manaus, com as coordenadas geográficas 0259'34', - S e 5958'38',- W, a cerca de $15 \mathrm{~km}$ de distância da margem esquerda do rio Negro. Os trabalhos arqueológicos no local ocorreram em duas etapas, em 2001 e em 2004, por meio do "Programa de Resgate Arqueológico do Sítio Nova Cidade", que foi solicitado pelo IPHAN [31] e Ministério Público Federal (AM) para avaliação dos danos causados ao sítio arqueológico em função da construção de um conjunto habitacional. As obras eram de responsabilidade da Superintendência de Habitação e Assuntos Fundiários do Estado do Amazonas (SUHAB-AM), quando os trabalhos de terraplanagem, realizados em 2000 e 2001, ocasionaram a destruição do sítio arqueológico, contribuindo para a perda de muitos dados a ele relativos [26]. Descoberto há a onze anos quando no processo de expansão da cidade, por conta das obras de construção de casas populares durante os trabalhos de terraplanagem que removeram cerca de um metro de espessura da camada de terra preta do local. A área está localizada a $15 \mathrm{~km}$ da margem esquerda do Rio Negro, possui 12,7 ha é de propriedade da Superintendência Estadual de Habitação do Amazonas (SUHAB-AM).

O estudo terá como base, o monitoramento do processo erosivo acelerados em uma voçoroca no Cemitério Arqueológico Indígena Bairro do Nova Cidade. O sítio Nova Cidade (AM-MA38), localizado na área urbanizada de Manaus, foi identificado em 2000, por ocasião da construção de moradias em um conjunto habitacional - obra gerenciada pela Superintendência de Habitação e Assuntos Fundiários do Estado do Amazonas (SUHAB).

Os trabalhos ligados ao resgate arqueológico ocorreram em 2001 e em 2004, por uma equipe composta por arqueólogos integrantes do PAC. Desde então, nenhuma ação concreta visando à recuperação da área foi efetivada, a despeito das orientações dadas nos relatórios [26]. Hoje, o local encontra-se exposto ao abandono, violência e à degradação. Dentro desta perspectiva, a Geomorfologia Urbana pode proporcionar uma reflexão séria sobre questões que continuam a fazer parte do nosso quotidiano, abrindo novos cenários científicos, culturais e sociais que proporcionem à sociedade uma visão diferente, sobre o próprio espaço em que se insere. A Geomorfologia é o estudo das formas do relevo, levandose em conta a natureza, origem, desenvolvimento de processos e a composição dos materiais envolvidos. Todos estes aspectos fazem parte do corpo teórico conceitual e aplicado de centenas de artigos, livros, relatórios, monografias, dissertações e teses, exaustivamente abordadas nessas publicações espalhadas pelo mundo [14]. Geomorfologia Urbana, que busca compreender os rápidos processos de metamorfoses ocorridos pela dinâmica dos espaços naturais agora ocupados por edificações e suas consequentes pressões sobre o meio físico urbano.

\section{MATERIAIS E MÉTODOS}

$\mathrm{Na}$ abordagem da coleta de dados que compreendeu o Sistema de Informações Geográficas (SIG) em campo foi utilizado, sensor MAP 78 para captação de satélite GPS na identificação das coordenadas geográficas, câmera GroPro Hero 4K, notebook para tratamento de dados de imagens de satélite, e um Veículo Aéreo Não Tripulado (Vant), Quadricóptero Phantom Vision 2 V3 onde foi feito um voo localizado no Cemitério Indígena para captação de imagem dos processos erosivos. Para os estudos correspondente a área da Geomorfologia Urbana, foram analisados os tipos, níveis e classificação dos processos erosivos atuante no local e seus reflexos sinérgicos à vida do homem.

Os métodos para tal análise teve o embasamento apoiado por obras de teóricos como: [4], entre outros autores que tratam sobre problemas originalmente físicos, mas que sofrem interferências antropogênica no ambiente. Procuramos a desenvolver um estudo baseado em princípios de análises qualitativas através de estudos de campo, observações e coletas de dados nos locais estudados. Foram realizadas análises empíricas de pesquisas de campo voltadas a identificar os problemas causados por processos erosivos. As áreas afetadas do cemitério arqueológico indígena foram monitoradas em julho e agosto, totalizando duas visitas de campo em todas as áreas trabalhadas.

\section{RESULTADOS E DISCUSSÕES}

O sítio arqueológico caracteriza-se pela grande quantidade de materiais cerâmicos e líticos expostos na superfície em uma área de aproximadamente 12,7 ha. As ocorrências ocupam um topo aplainado e vertentes suaves, com solo exposto de característica areno-argilosa e cor amarela, uma vez que os pacotes arqueológicos e a matriz sedimentar original, composta pelas terras pretas antrópicas, foram removidos durante as obras de terraplanagem [26]. Através das análises dos vestígios culturais recolhidos no sítio Nova Cidade, que se deram, inclusive, no âmbito de uma pesquisa de cientifica [32], foi possível inseri-lo dentro dos parâmetros da cronologia regional. Isso em função do conhecimento razoavelmente bem consolidado sobre a sequência de ocupação da Amazônia central [26] e também pelo fato dos materiais apresentarem elementos bastante característicos dos conjuntos já conhecidos na região [34].

As pesquisas não foram muito além desta primeira identificação, e não foram feitas escavações mais extensas ou datações destes sítios [33]. A pesar dos problemas enfrentados pelos pesquisadores para classificar e datar os vestígios materiais encontrados, sobretudo aqueles que apresentam datações anteriores há 700 anos, diversas e valiosas informações já foram apresentadas. Ao IPHAN compete o exame, registro, fiscalização e salvaguarda 
do interesse da ciência (art.4. Lei 3924/61), a autorização de saída de material arqueológico do país, qualquer tipo de atividade que implique em uso, mudança de uso ou de proteção dos sítios como a implantação de empreendimentos de grande porte e turismo.

Os estudos dos processos erosivos nas áreas enfocadas sugerem uma dinâmica ativa envolvendo em sinergia vários fatores conjugados como o elevado índice pluviométrico presente na área, associado a morfologia do terreno que contribui para que áreas mais baixas receba fluxos concentrados de água [35]. Além dos processos erosivos atuarem intensamente nos sedimentos silticosargilosos que auxiliarão no desenvolvimento das voçorocas. A recuperação de áreas degradadas necessita de um conjunto de medidas institucionais e procedimentos de ordem geotécnica para controle das erosões [36].

\section{CONCLUSÃO}

Estudando o ambiente e apropriação do relevo em áreas urbanas tornou-se um desafio, principalmente pela grande transformação que o relevo passa. Os obstáculos enfrentados neste tipo de pesquisa referem - se à metodologia, ao método, aos conceitos que possam integrar as dinâmicas da sociedade e da natureza e como essas dinâmicas se materializam no espaço gerando uma paisagem artificial. A Geomorfologia Urbana seria aquela que envolve em suas análises a produção do espaço urbano e os interesses dos agentes de produção deste espaço no relevo. $\mathrm{O}$ relevo neste cenário de produção, além de servir como suporte físico para as edificações resultantes da produção social, passa a ser considerado como mercadoria na visão dos agentes de produção do espaço urbano. A partir da inter-relação das dinâmicas da sociedade (envolvendo o processo de apropriação e ocupação dos compartimentos do relevo etc.) e da natureza (abrangendo a dinâmica hídrica, pedológica, atmosférica etc.), os compartimentos geomorfológicos sofrem uma aceleração dos processos de esculturação e com os resultados desta dinâmica temos a manifestação de diversos impactos sociais e ambientais, além do surgimento de novas morfologias tecnogênicas. Os processos erosivos estão em crescimento exponencial, contabilizando prejuízos para e observou-se, por força desse processo, a intensa modificação da área de estudo da região, processo de assoreamento do igarapé. O controle da erosão por voçorocas é uma operação difícil, já que normalmente, o usuário que concorre para sua formação ignora que, em conservação dos recursos naturais, é sempre mais econômico preservar do que restaurar. O que pode ser controlado é o escoamento superficial da água da chuva sobre o terreno, evitando piorar a erosão do solo que compromete tanto o terreno erodido como a região que recebe os sedimentos gerados, com a utilização de meios simples de contenção, como represamento de água das chuvas formando lagoas para que essas não escorram superficialmente.

\section{AGRADECIMENTOS}

A Sonia Albuquerque Freitas por orientado nesta pesquisa. Profa. Coordenadora Helen Rita Menezes Coutinho por ter intermediado junto ao UNINORTE, nesta pesquisa.

\section{VI.REFERÊNCIAS}

[1] Rodrigues, T.F.; Costa, R.C. Geomorfologia Urbana e Riscos em Manaus (AM). REVISTA GEONORTE, Edição Especial 4, V.10, N.1, p.35-40, 2014.

[2] Santos Junior, E.V. da C. Identificação e Análise Geoambiental de processos erosivos em uma porção da área urbana de Manaus-AM (bairros Cidade Nova e Mauazinho). (Dissertação de Mestrado). Manaus: CCA/UFAM.2002.

[3] Santos. Rozely Ferreira dos (org). Vulnerabilidade Ambiental. - Brasília: MMA, 2007

[4] Guerra, A.J.T. Processos erosivos nas encostas. In: Guerra, A. J.T. \& Cunha, S.B. da. Geomorfologia: uma atualização de bases e conceitos. $11^{\mathrm{a}}$ ed. Rio de Janeiro: Bertrand Brasil. 2012.

[5] Guerra. Antônio José Teixeira. Jorge Maria do Carmo Oliveira. Processo Erosivos e Recuperação de Áreas Degradadas. São Paulo. Oficina de Texto,2013.

[6] Cassiano, Karla Regina Mendes; Costa, Reinaldo Corrêa. Identificação das Áreas de Risco de Manaus (AM), Brasil. In: 12 Encuentro de Geografos de America Latina, 2009, Montevideo. Caminando em una America Latina en Transformacion. Montevideo, 2009.

[7] Oliveira, Luís Marcelo. Acidentes Geológicos Urbanos. MINEROPAR. Serviço Geológico do Paraná. 1ª Edição. Curitiba, 2010 .

[8] Prandini, Fernando Luiz; NAKAZAWA, Valdir Akihiko. A erosão urbana, algumas considerações. In: $5^{\circ}$ Simpósio Nacional de Controle de Erosão, 5. 1995.ANAIS.

[9] Magalhães, Ricardo Aguiar. Erosão: Definições, Tipos e Formas de Controle. VII Simpósio Nacional de Controle de Erosão. Goiânia (GO), 2001.

[10] Guerra, Antônio José Teixeira. Experimentos e monitoramentos em erosão dos solos. Revista do Departamento de Geografia, 16.32-37. 2005.

[11] Guerra, A. J. T; Cunha. S. B. Geomorfologia e Meio Ambiente. 9a ed. Bertrand Brasil, Rio de Janeiro. 2010.

[12] Guerra, Antônio J. T. (Org.). Geomorfologia Ambiental. São Paulo: Bertrand Brasil,2006.

[13] Guerra, A. J. T. e Cunha, S. B. da. (Orgs). Impactos Ambientais Urbanos no Brasil. $5^{\text {a }}$ ed. Rio de Janeiro, Bertrand Brasil, 2009.

[14] Guerra, A. J.T. \& Cunha, S.B. Geomorfologia Urbana. Rio de Janeiro, Bertrand Brasil. 2011.

[15] Guerra, A. T. e Guerra, A.J.T. Novo dicionário Geológico Geomorfológico. Rio de Janeiro, Bertrand Brasil. 2010.

[16] Guerra, A.J.T. Encostas e a Questão Ambiental. In: Guerra, A. J.T.; Cunha, S. B. (orgs.) A questão ambiental: diferentes 
abordagens. 6 ${ }^{\text {a }}$ ed.-Rio de Janeiro: Bertrand Brasil, 2010, p.191218.

[17] Lepsch, Igor. F. Formação e conservação do solo. $2^{\mathrm{a}}$ reimpressão. São Paulo: Oficina de Textos, 2007.

[18] Baccaro, Claudete Aparecida Dalevedove. As unidades morfológicas e a erosão nos chapadões do Município de Uberlândia, 1994.

[19] Magalhaes, Ricardo Aguiar. Processos Erosivos e Métodos de Contenção. CEEB, Ouro Preto, 1995.

[20] Prado, Rachel Bardy. Manejo e conservação do solo e da água no contexto das mudanças ambientais. Rio de Janeiro: Embrapa Solos, 2010.

[21] Vieira, Antônio Fábio Guimarães. Desenvolvimento e Distribuição de Voçorocas em Manaus (AM): Principais Fatores Controladores e Impactos Urbanos-Ambientais (Tese de doutorado). UFSC. 2008.

[22] Suguro, K. Geologia Sedimentar, São Paulo: Ed. Edgard Blucher. 2003.

[23] Zoccal, José Cezar. Soluções cadernos de estudos em conservação do solo e água. Presidente Prudente: CODASP, 2007.

[24] Guerra, A.J.T.; Silva, A.S.; \& Botelho, R.G. M. (Org). Erosão e Conservação dos Solos: Conceitos, Temas e Aplicações. 10 Ed. Rio de Janeiro. Bertrand Brasil. 2015.

[25] Guerra, Antônio Jose Teixeira. Jorge, Maria do Carmo Oliveira. Geomorfologia do cotidiano - a degradação dos solos. REVISTA GEONORTE, Edição Especial, V.4, N.4, p.116 - 135, 2012.

[26] Neves, Eduardo Góes. Arqueologia da Amazônia. Rio de Janeiro: Jorge Zahar, 2006.

[27] Santos, Luana Maria dos. Erosão em taludes de corte: métodos de proteção e estabilização. Trabalho de Graduação em Engenharia Civil - Universidade Estadual Paulista - UNESP. Faculdade de Engenharia de Guaratinguetá, 2014.

[28] Araújo, G.H.S., Almeida, J.R. e Guerra, A.J.T. Gestão Ambiental de Áreas Degradadas. Rio de Janeiro, Editora Bertrand Brasil, 6 ${ }^{a}$ edição. 2010.

[29] IBGE: Instituto Brasileiro de Geografia e Estatística.www.ibge.gov.br> acesso dia 10/09/2016.

[30] https://maps.google.com.br/. 2016. acesso dia 11/10/2016.

[31] IPHAN.GOV.BR > acesso dia 10/09/2016.

[32] Parnassinen Martti et al., Geoglifos de Amazônia ocidental: evidencia e complexiibilidade social entre povos da terra firme. Revista de Arqueologia. 20, 27-82, 2007.
[33] Almeida, José A. P. de. Aragão, Ricardo de; Figueiredo, Eduardo E. de; Srinivasan. Vajapeyam S. Mapeamento do potencial de erosão laminar na bacia do Rio Japaratuba, SE, via SIG. Revista Brasileira de Engenharia Agrícola e Ambiental, Rev. vol.15 no.7 Campina Grande July 2011.

[34] Santos, A. S.; Alves, S. D. M.; Figueiredo, F. J. C.; Neto, O. G. D. R. Descrição de Sistema e de Métodos de Extração de Óleos Essenciais e Determinação de Umidade de Biomassa em Laboratório. Ministério da Agricultura, Pecuária e Abastecimento. Belém-PA, 2004.

[35] Probst, I. S. Atividade antibacteriana de óleos essenciais e avaliação de potencial sinérgico. Dissertação (Mestrado)Universidade Estadual Paulista, Instituto de Biociências de Botucatu, 2012.

[36] Otto I, Heribert O. Patents Process for the recovery of pure alpha-bisabolol. United States Patent A US3932533. CA1013373A, CA1013373A1, DE2317583A1, DE2317583B2, DE2317583C3.1976. 